\title{
Nurses, Healthy Women and Preventive Gynecological Examinations - Vlora City Scenario, Albania
}

\author{
Fatjona Kamberi $^{1 *}$, Gjergji Theodhosi ${ }^{2}$, Vjollca Ndreu ${ }^{2}$, Enkeleda Sinaj ${ }^{2}$, Yllka \\ Stramarko ${ }^{1}$, Leonard Kamberi ${ }^{3}$
}

\begin{abstract}
Background: Nurses play an important role in preventive medicine because they represent the largest sector of health professionals. This role is very crucial in developing countries, which are going through rapid societal and economic changes, associated with a rising burden of cancers due to different risk factors. The current study aimed to compare health awareness between nurses and healthy women regarding preventive gynecological examinations and to answer the question - can nurses make a difference in women's health? Materials and Methods: This cross sectional research included a total of 150 women, 70 nurses and 80 healthy women, randomly selected. Data were collected in 2014 in Vlora city through a self-administered questionnaire that assessed different variables about preventive gynecological examinations. Results: Cervical screening rates were $20.3 \%$ and $\mathbf{4 1 . 8 \%}$, respectively, for nurses and healthy women, despite the former having a statistical significant greater knowledge of risk factors and symptoms. Conclusions: Even if the health awareness of nurse participants can be considered good, they need themselves to increase participation rates in cervical screening if they are to provide role models for health education/promotion addressing misconceptions and barriers.
\end{abstract}

Keywords: Nurse - cervical cancer - gynecological examination - women - health education/promotion - Albania

Asian Pac J Cancer Prev, 17 (1), 311-314

\section{Introduction}

Generally, worldwide trends show that in developing countries going through rapid societal and economic changes, the shift towards lifestyles typical of industrialized countries leads to a rising burden of cancers associated with different risk factors. Breast cancer worldwide is affecting more than half a million of women every year and cervical cancer is the fourth most common cancer affecting women worldwide, after breast (Ferlay et al., 2014). A study conducted by Bray et al. (2012) found that nine different cancers were the most commonly diagnosed in men across 184 countries, with cancers of the prostate, lung, and liver being the most common. Breast and cervical cancers were the most common in women.

Different studies have demonstrated some positive effects of interventions by specialist nurses for women in the prevention of gynecological cancers (Cook et al., 2015). It is necessary for nurses to educate women about cervical cancer, to have an awareness of the mortality rates associated with cervical cancer, and to promote the cervical cancer screening. Therefore, nurses practitioners have an opportunity to impact the incidence and mortality of cervical and breast cancer by improving screening practices (Bedford, 2009; Reis at el., 2012). An overview of cervical cancer knowledge and screening among female healthcare practitioners (HCPs) study, evidenced a small percentage of nurses who had ever had a Pap smear (Kamberi et al., 2014). The same study addressed the insufficiency of training staff, materials and the lack of laboratory facility for effective screening services. Low prevalence of women screened among female HCPs shows that they primarily do not care for themselves, even though they are responsible for the health education and screening promotion. Providing adequate training on the necessity of early referral could also be effective in improving woman's awareness and performance (Farshbaf et al., 2014).

\section{Materials and Methods}

The study was conducted in 2014-2015 in Vlora city including 70 nurses and 80 healthy women controls to assess the cervical cancer screening. The study was a self- administered questionnaire-based comparative crosssectional study. In the questionnaire were included sociodemographic variables (age, marital status, empoyment, level education), questions about cervical cancer symptoms and risk factors knowledge, Pap smear uptake for nurses and controls and the reasons that influences the opportunistic Pap test uptake.

The sample was randomly selected, for both nurses 
Fatjona Kamberi et al

and controls. The age interval was 25-65years. Healthy women were defined all women who were in employment status without a presents of illness. Crosstabulation $(\mathrm{MxN})$ tables and, $\mathrm{X}^{2}$ test / Fisher test were employed to compare the proportion between the two groups. A value of $\mathrm{P} \leq$ 0,05 was considered statistically significant. EpiInfoTM 7 software version 7.1.3.10 was used for statistical calculation (CD-C Epi InfoTM). Ethical approval was granted by the relevant ethics committees, and written informed consent was obtained from each participant after they were fully informed of the detilaed plan and goals of the study.

\section{Results}

A total of 150 women (71 nurses and 79 healthy women group) were the sample study. The average age of nurses group was 37.00 years \pm 8.5 (range 25-65) and the average age of the healthy women controls was 38.00土8.2years (range 25-65).

The main barriers cited from the participants in the study to effective screening services were insufficent training staff $68.57 \%(\mathrm{n}=48), 95 \mathrm{CI}$ [56.37- 79.15], $\mathrm{P}=0.0$ and the lack of laboratory facility,82.86\% $(n=58),[71.97$ $-90.82], \mathrm{P}=1.0$.

Table 1. Socio-demographic Characteristics of the Subjects Studied

\begin{tabular}{|c|c|c|c|c|}
\hline \multicolumn{5}{|c|}{ a) The level of education } \\
\hline Education level & $\mathrm{N}(\%)$ & $95 \% \mathrm{CI}$ & $\mathrm{N}(\%)$ & $95 \% \mathrm{CI}$ \\
\hline Lower education & $0(0)$ & {$[0.0-5.44]$} & $17(21.51)$ & [13.06-32.20] \\
\hline Higher education & $0(0)$ & {$[0.0-5.44]$} & $7(8.86)$ & [3.64-17.41] \\
\hline University degree & $71(100)$ & {$[100-100]$} & $55(69)$ & {$[58.25-79.47]$} \\
\hline \multicolumn{5}{|c|}{ b) Civil status distribution } \\
\hline \multirow[t]{2}{*}{ Civil status } & \multicolumn{2}{|c|}{ Nurse group } & \multicolumn{2}{|c|}{ Healthy women group } \\
\hline & $\mathrm{N}(\%)$ & $95 \% \mathrm{CI}$ & $\mathrm{N}(\%)$ & $95 \% \mathrm{CI}$ \\
\hline Married & $66(92.42)$ & {$[83.2-97.49]$} & $71(89.87)$ & [81.02-95.53] \\
\hline Single & $0(0.0)$ & {$[0.00-5.44]$} & $5(6.33)$ & {$[2.09-14.16]$} \\
\hline Divorced & $5(7.58)$ & {$[2.51-16.8]$} & $3(0.79)$ & {$[0.79-10.70]$} \\
\hline \multicolumn{5}{|c|}{ c) Employment status distribution } \\
\hline Employment status & $\mathrm{N}(\%)$ & $95 \% \mathrm{CI}$ & $\mathrm{N}(\%)$ & $95 \% \mathrm{CI}$ \\
\hline Yes & $70(100)$ & {$[100-100]$} & $70(89.74)$ & {$[80.79-95.47]$} \\
\hline No & $0(0.0)$ & {$[0.0-0.0]$} & $10(10.26)$ & {$[4.53-19.21]$} \\
\hline
\end{tabular}

Table 2. Knowledge of Cervical Cancer Symptoms and Risk Factors

\begin{tabular}{|c|c|c|c|c|c|}
\hline $\begin{array}{l}\text { a) Knowledge of cervical cancer symptoms } \\
\text { Variables }\end{array}$ & Nurses $(\%)(\mathrm{n})$ & $95 \% \mathrm{CI} \quad \mathrm{H}$ & Healthy women $(\%)(\mathrm{n})$ & $95 \% \mathrm{CI}$ & $P$ value \\
\hline Abnormal vaginal discharge $(\mathrm{t})$ & $47.17 \%(n=25)$ & [33.30-61.36] & $15.19 \%(\mathrm{n}=12)$ & {$[8.10-25.03]$} & 0.0055 \\
\hline Vaginal bleeding $(\mathrm{t})$ & $47.17 \%(n=25)$ & [33.30-61.36] & $29.11 \%(n=23)$ & {$[19.43-40.42]$} & 0.12 \\
\hline Bleeding after sexual intercourse $(\mathrm{t})$ & $52.83 \%(\mathrm{n}=28)$ & [38.64-66.70] & $13.92 \% \quad(n=11)$ & {$[7.16-23.55]$} & 0.0005 \\
\hline Vaginal bleeding after menopause $(\mathrm{t})$ & $39.62 \%(\mathrm{n}=21)$ & {$[26.45-54.00]$} & $18.99 \% \quad(\mathrm{n}=15)$ & {$[11.03-29.38]$} & 0.066 \\
\hline \multicolumn{6}{|l|}{ b) Knowledge of cervical cancer risk factors } \\
\hline Variables & Nurses $(\%)(\mathrm{n})$ & $95 \% \mathrm{CI} \quad \mathrm{I}$ & Healthy women $(\%)(\mathrm{n})$ & $95 \% \mathrm{CI}$ & $P$ value \\
\hline Woman don't get a regular pap test (t) & $28.30 \%(\mathrm{n}=15)$ & [16.79-42.35] & $25.32 \%(\mathrm{n}=20)$ & {$[16.20-36.36]$} & 1 \\
\hline Woman has sexually infections(t) & $58.49 \%(n=31)$ & [44.13-71.86] & $5.06 \%(n=4)$ & {$[1.40-12.46]$} & 0 \\
\hline Woman smokes $(\mathrm{t})$ & $38.57 \%(\mathrm{n}=28)$ & [27.17-50.97] & $12.66 \%(\mathrm{n}=10)$ & {$[6.24-22.05]$} & 0.0006 \\
\hline Woman has 2 or more sexual partners (t) & $61.43 \%(n=43)$ & [49.03-72.83] & $41.77 \%(n=33)$ & {$[30.77-53.41]$} & 0.01 \\
\hline Woman started sexual intercourse before the age of 20 years ( $t$ ) & $55.71 \%(\mathrm{n}=39)$ & [43.34-67.59] & $17.72 \%(\mathrm{n}=14)$ & {$[10.04-27.94]$} & 0.000001 \\
\hline
\end{tabular}

$(t)=$ the correct answer to the item is "true;" (f)=the correct answer to the item is "false;"

Table 3. Association between Being a Nurse and Pap Test Uptake

\begin{tabular}{|c|c|c|c|c|c|}
\hline \multirow[t]{2}{*}{ Variables } & \multicolumn{2}{|c|}{ Nurses $(\%)(\mathrm{n})$} & \multicolumn{2}{|c|}{ Healthy women $(\%)(\mathrm{n}$} & \multirow[t]{2}{*}{ P value } \\
\hline & Yes $(\%)(\mathrm{n})$ & $\mathrm{No}(\%)(\mathrm{n})$ & Yes $(\%)(\mathrm{n})$ & No $(\%)(n)$ & \\
\hline Have you ever had a Pap smear & $20.29 \%(\mathrm{n}=14)$ & $79.71 \%(\mathrm{n}=55)$ & $41.77 \%(\mathrm{n}=33)$ & $58.23 \%(\mathrm{n}=46)$ & 0.004 \\
\hline \multicolumn{6}{|c|}{ Reasons for not attending cervical screening } \\
\hline \multirow[t]{2}{*}{ Variables } & \multicolumn{2}{|c|}{ Nurses $(\%)(\mathrm{n})$} & \multicolumn{2}{|c|}{ Healthy women $(\%)(\mathrm{n})$} & P value \\
\hline & Yes $(\%)(\mathrm{n})$ & $\mathrm{No}(\%)(\mathrm{n})$ & Yes $(\%)(\mathrm{n})$ & No $(\%)(n)$ & \\
\hline Lack of syn & $68.57 \%(\mathrm{n}=48)$ & $31.43 \%(n=22)$ & $53.16 \%(n=42)$ & $46.84 \%(n=37)$ & 0.065 \\
\hline Dislike of gynecologic examinations & $8.57 \%(\mathrm{n}=6)$ & $91.43 \%(n=64)$ & $8.86 \%(\mathrm{n}=7)$ & $91.14 \%(n=72)$ & 1 \\
\hline Lack of service delivery & $8.57 \%(\mathrm{n}=6)$ & $91.43 \%(\mathrm{n}=70)$ & $18.99 \%(\mathrm{n}=15)$ & $81.01 \%(n=64)$ & 0.43 \\
\hline
\end{tabular}




\section{Discussion}

The study was conducted with the objective of finding out the factors that determine the health awareness between nurses and healthy women on preventive gynecological examinations and how can nurses make a difference in women's health. Between 70 nurses and 80 healthy women not differences were found in socio-demographic variables in terms of age, marital and employment status. Of all women participants in the study regarding level of education, prevalent (Table 1) is the university degree $(n=71)$ for nurses and $(n=55)$ for the healthy women. For instance, studies find that women who have low health literacy are significantly more likely to have never had a Pap smear in their life, or not to have had a mammogram in the past two year. In a study conducted by Stark A at al. (2008), younger and more educated women who participated in this study were more likely to know about the risk of cervical cancer. Also, age and education were the two variables that were statistically associated with the outcome. Regarding marital status, almost all women in the study (nurses and healthy women) were married (Table 1). A study found that marital status is significantly associated with cervical cancer screening adherence. Also, single/separated/divorced/widowed status, the non-housewives and women with no children are more vulnerable to cancer screening adherence (Visanuyothin et al., 2015). Employment status is another determinant of cervical cancer screening adherence. Table 1, shows that almost all women were employed. A study conducted by Yanikkerem et al., 2013 found that employed women had regular gynaecological examination. No statistically significance was found between nurses and healthy women about socio-demographic characteristics. Even though a systematic review found that all socio-demographic variables included in Table 1 to be significantly associated with adherence to screening included education, financial status, acculturation, psychosocial issues, and marital status (Limmer et al., 2014).

Table 2 shows the association between knowledge of cervical cancer symptoms and risk factors in nursing group and in controls. Cigarette smoking, both active and passive, (Roura et al., 2014; Henley et al., 2014), high number of full-term pregnancies (Muñozet al., 2002) long-term use of oral contraceptives (Moreno et al., 2002) and a higher number of sexual partners like the main risk for the acquisition of HPV infection (Remschmidt et al., 2013) increases the risk of cervical cancer. Poverty is also a risk factor for cervical cancer. Many low-income women do not have ready access to adequate health care services, including Pap tests. This means they may not get screened or treated for cervical pre-cancers (ACS, 2013). As, it is shown from this table, by the four variables about cervical cancer symptoms included in the questionnaire only two of them are statistically significant. The awareness of cervical cancer symptoms among female care practitioners is a predictor for the early detection and diagnosis of cervical cancer (Chacko, 2014). Moreover, for the variables about cervical risk factors only two were statistically significant, smoking (38.57\% of nurses) and starting the sexual intercourse before the age of 20 years ( $55.71 \%$ of nurses).
The results of the study are similar with a study conducted by Yaren A et al. (2008) among nurses in rural region.

The Papanicolau (Pap) smear is the single most successful cancer screening tool in modern medicine. Based on evidence, screening via regular Pap smear decreases the incidence and mortality of cervical cancer (Justin \& Dana 2012; Sengul et al., 2014). But the results in Table 3 shows that the rates of Pap smears uptake among nurses are very low, and a half of healthy women in the study were screened, $p=0.004$. The low level of Pap smear uptake is consistent with findings in studies made in other developing countries were only $13 \%$ of female health care practitioners had ever had a Pap smear. Also a low rate of Pap smear test among nurse was found in a study carry out by Isil I.K A. \& Asiye G. (2015) while $39.8 \%$ of them did not take a Pap smear test since they did not think it was necessary. It was observed that the lack of symptoms was the only factor significantly associated with Pap smear test uptake on multivariate linear regression analysis (Table 3 ). To improve health promotion behaviours in women should consider health literacy as an important factor and that the effect of health literacy on health prevention behaviours may vary by women's access to care (ShoouYih et al., 2012).

In conclusion, In Albania, no national screening program for cervical cancer conducted yet and studies indicated that female health care practitioners and women`s awareness of cervical cáncer, warning signs and effective screening were very inadequate (Kamberi et al., 2014a; 2014b). Even if the present study confirm this fact, nurses with their knowledge, practice and health education of their patients can do more, because saying and doing can save lives. Training programs for nurses and health education programs about preventive gynecological examinations would be beneficial to reduce the lack of women's awareness regarding cervical cancer, to control morbidity and mortality rates. In conclusion, Pap smear coverage in this study at $20.29 \%$ among nurses and $41.77 \%$ among healthy women is far lower than global average and even below the average for developing countries. Health education programs which are effective not only in increasing knowledge but also in bringing about positive effects of health literacy in women towards pap smear test should be organized to increase Pap smear adherence among women in general in Vlora city.

\section{References}

American Cancer Society (2013). http://www.cancer.gov/ cancertopics/screening/pap-tests-cervical-health.

Bedford S (2009).Cervical cancer: physiology, risk factors, vaccination and treatment. Br J Nurs, 18, 80-4.

Bray F, Jemal A, Grey N, et al (2012). Global cancer transitions according to the Human Development Index (2008-2030): a population-based study. Lancet Oncol, 13, 790-801.

Chacko S (2014). Effect of structured teaching programme on VIA test for early detection and diagnosis of cervical cancer. Nurs J India, 105, 221-4.

Cook O, McIntyre M, Recoche K (2015). Exploration of the role of specialist nurses in the care of women with gynaecological cancer: a systematic review. J Clin Nurs, 24, 683-95. 
Farshbaf-K. A, Salehi-P. H, Shahnazi M, et al (2015). Effect of structured teaching programme on VIA test for early detection and diagnosis of cervical cancer, Nurs $J$ India. $\mathbf{1 0 5}, 221-4$.

Fatjona K, Gjergji Th, Yllka B, et al (2014).An overview of cervical cancer knowledge and screening among female health care practitioners. Eur Scientific J, 10,30.

Fatjona K, Gjergji Th, Vjollca N, et al (2014). Vlora womens and cervical cancer screening: a study of awareness and barriers. J MacroTrends Health and Med, 2. 120-30.

Ferlay J, Steliarova-Foucher E, Lortet-Tieulent J, et al ( 2014). Cancer incidence and mortality patterns in Europe: estimates for 40 countries in 2012. Eur J Cancer, 49, 1374-403.

Henley SJ, Singh S, King J, et al (2014). Invasive cancer incidence - United States, 2010. MMWR Morb Mortal Wkly Rep, 63, 253-9.

Isil I. A, Asiye G (2015). Breast, cervix and colorectal cancer knowledge among nurses in Turkey. Asian Pac J Cancer Prev, 15, 2267-72.

Justin L, Dana R. G (2012). Evidence-Based Cervical Cancer Screening: The Modern Evolution of the Pap Smear, Evidence Based Medicine - Closer to Patients or Scientists?, Prof. Nikolaos Sitaras (Ed.), ISBN: 978-953-51-05046, InTech, Available from: http://www.intechopen.com/ books/evidencebased-medicine-closer-to-patients-orscientists-/evidence-based-cervical-cancer-screening-themodernevolution-of-the-pap-smear.

Karen L, Geri L.-W, Joyce D (2014). Predictors of cervical cancer screening adherence in the United States: A Systematic Review. J Adv Pract Oncol, 5, 31-41.

Moreno V, Bosch FX, Muñoz N, et al (2002): Effect of oral contraceptives on risk of cervical cancer in women with human papillomavirus infection: the IARC multicentric case-control study. Lancet, 359, 1085-92.

Muñoz N, Franceschi S, Bosetti C, et al (2002). Role of parity and human papillomavirus in cervical cancer: the IARC multicentric case-control study. Lancet, 359, 1093-101.

National Cancer Institute (2014). Cervical Cancer Screening; 07/09/2014 09:17 AM EDT.

Nesrin R, Hatice B, Sevinc K, et al (2012). Knowledge, behavior and beliefs related to cervical cancer and screening among Turkish women. Asian Pac J Cancer Prev, 13, 1463-70 .

Remschmidt C, Kaufmann AM, Hagemann I, et al (2013). Risk factors for cervical human papillomavirus infection and high-grade intraepithelial lesion in women aged 20 to 31 years in Germany. Int J Gynecol Cancer, 23, 519-26.

Roura E, Castellsagué X, Pawlita M, et. al (2014). Smoking as a major risk factor for cervical cancer and pre-cancer: Results from the EPIC cohort. Int J Cancer. 135, 453-66.

Sengul D, Altinay S, Oksuz H, et al (2014). Population-based cervical screening outcomes in Turkey over a period of approximately nine and a half years with emphasis on results for women aged 30-34. Asian Pac J Cancer Prev, 15, 2069-74.

Shoou-Yih D. Lee,Tzu-I T, Yi-Wen T, et al (2012). Health literacy and women's health-related behaviors in Taiwan. Health Educ Behav, 3, 75.

Stark A, Gregoire L, Pilarski R, et al (2008).Human papillomavirus, cervical cancer and women's knowledge. Cancer Detect Prev, 32, 15-22.

Visanuyothin S, Chompikul J, Mongkolchati A (2015). Determinants of cervical cancer screening adherence in urban areas of Nakhon Ratchasima Province, Thailand. $J$ Infect, 8, 543-52.

Yanikkerem E, Goker A, Piro N, et al (2013) Knowledge about cervical cancer, pap test and barriers towards cervical screening of women in Turkey. J Cancer Educ, 28, 375-83. 